\title{
Biosynthesis of pro-opiomelanocortin is increased in the rat intermediate pituitary following denervation
}

\author{
Monica A. Seger ${ }^{1}$, Jozsef Z. Kiss*, Hubert H.M. van Tol and \\ J. Peter H. Burbach \\ Rudolf Magnus Institute for Pharmacology, Medical Faculty, University of Utrecht, Utrecht \\ (The Netherlands)
}

(Received 14 May 1987; Revised version received 31 July 1987; Accepted 4 August 1987)

Key words: Denervated intermediate pituitary; Pro-opiomelanocortin (POMC) synthesis; High-performance liquid chromatography

In order to study the effect of pituitary intermediate lobe denervation on pro-opiomelanocortin (POMC) biosynthesis and processing, radioactive amino acids were incorporated in vitro into whole neurointermediate lobe (NIL) explants obtained from hypothalamic lesioned rats and control animals. The lesion in the basal hypothalamus removed the neural input to the intermediate pituitary and cut the neurohypophyseal neurons. One week after the lesion, approximately a 3-fold increase in the rate of synthesis of POMC peptides was found in the NIL. The content of POMC peptides was decreased. The results imply that denervation increases the rate of POMC synthesis and release, without altering the pattern of proteolytic processing.

The pro-opiomelanocortin (POMC)-synthesizing cells in the anterior lobe (AL) and intermediate lobe (IL) of the pituitary gland differ in the regulation of POMC gene expression, biosynthesis and release as well as in the nature of the peptides formed. In the rat AL, specific enzymatic cleavages of the precursor yield an aminoterminal glycopeptide of 74 amino acids (also referred to as $16 \mathrm{~K}$ fragment), several forms of $\mathrm{ACTH}$, and $\beta$-LPH which is partially processed to $\beta$-endorphin $[9,11]$. In the IL, POMC is processed more extensively: cleavage occurs at virtually all of the dibasic sites. The smaller products formed in this tissue are a non-glycosylated 49residue $N$-terminal fragment [3], [Lys ${ }^{1} \gamma_{3} \mathrm{MSH}$ [5], $\alpha$-MSH and $\mathrm{CLIP}\left(\mathrm{ACTH}_{18-39}\right)$ [6], $\gamma$-LPH and several forms of endorphins [16]. Furthermore, POMC is subject to many post-translational modifications, namely glycosylation and phosphorylation [6], as well as amidation [12], acetylation [14] and endoproteolytic cleavages [16] following the formation of the major products.

\footnotetext{
*Present address: Institute of Histology and Embryology, University of Geneva Medical School, 1211 Geneva 4, Switzerland.

Correspondence: M.A. Seger, Rudolf Magnus Institute for Pharmacology, Vondellaan 6, 3521 GD Utrecht, The Netherlands.
} 
While the corticotrophs in the AL are controlled by humoral factors secreted into the hypophyseal portal blood such as corticotrophin-releasing factor (CRF) and vasopressin (VP), the IL is innervated from the basal hypothalamus by dopaminergic (DA), GABAergic and serotonergic fibers [4, 13], which control POMC biosynthesis and release. Both in vivo and in vitro studies with DA receptor agonists and antagonists have shown that DA tonically inhibits POMC synthesis and the release of products $[8,15]$. GABA also inhibits the release of IL products [21] while serotonin has a stimulatory effect on the secretion of POMC peptides from the IL [13].

Since the extent of precursor processing and post-translational modification has in many cases a dramatic effect on the biological activity of the products, it is of interest to determine what factors are involved in the control of these events and whether the different stimuli to which the two lobes of the pituitary are exposed may be partly responsible for the differential processing. As described above, the neural inputs to the IL affect both POMC synthesis and release. To study whether these inputs also modulate intragranular processing events, the tissue was denervated by a hypothalamic lesion and the rate of biosynthesis and the extent of processing and post-translational modifications were analyzed. The findings suggest that IL POMC synthesis and release are increased when the neural input is removed, while processing is not affected.

Surgeries were performed on fentanyl-anesthetized male Wistar rats $(150-160 \mathrm{~g})$. The animal's head was fixed in a Kopf stereotaxic instrument ( $0^{\circ}$ head position). To interrupt fibers travelling to the IL, a frontal cut at the level of the caudal third of the median eminence as made with a Halasz (bayonet-shaped) knife with a radius of $1.5 \mathrm{~mm}$ and a height of $1.2 \mathrm{~mm}$. The knife was inserted at $0.5 \mathrm{~mm}$ behind Bregma in the midline until the tip of the blade touched the floor of the skull. The tip had a rostral position initially and then it was rotated approximately $90^{\circ}$ to each side. In this way, the majority of the fibers passing toward the pituitary in the median eminence is lesioned $[4,20]$. The control animals were sham-operated. The rats were housed in individual cages with standard light conditions (lights on from 06.00 to $20.00 \mathrm{~h}$ ), and their weights and water consumptions were monitored daily. The animals were sacrificed one week after the lesion to prepare neurointermediate lobe (NIL) explants for the comparison of POMC biosynthesis in lesioned and control rats. Other animals were used for the immediate extraction of NILs to determine the content of POMC peptides. The brains were examined under a stereomicroscope to verify the position of the lesion, and together with the measurement of water consumption, was used as a criterion for the elimination of rats with incomplete lesions from the study. Altogether 6 correctly lesioned rats were selected for analysis.

The NILs were isolated in situ and placed individually in $100 \mu \mathrm{l}$ of sterile medium. The medium for incubation was Earle's basal salt solution containing 1\% horse serum, vitamins and all the essential amino acids except those which were used for radioactive labelling. The lobes were then transferred into $100 \mu \mathrm{l}$ of this medium containing $10 \mu \mathrm{Ci}$ each of $\left[{ }^{3} \mathrm{H}\right]$ serine $(11 \mathrm{Ci} / \mathrm{mmol})$ and $\left[{ }^{3} \mathrm{H}\right]$ leucine $(123 \mathrm{Ci} / \mathrm{mmol})$. They were incubated for $24 \mathrm{~h}$ at $37^{\circ} \mathrm{C}$ with $5 \% \mathrm{CO}_{2} / 95 \% \mathrm{O}_{2}$. At the end of the incubation period, the NILs were homogenized in $250 \mu \mathrm{l}$ of ice-cold $1 \mathrm{~N} \mathrm{HCl} \mathrm{extraction} \mathrm{medium}$ 
containing $5 \%(\mathrm{v} / \mathrm{v})$ formic acid, $1 \%(\mathrm{w} / \mathrm{v}) \mathrm{NaCl}$ and $1 \%(\mathrm{v} / \mathrm{v})$ trifluoroacetic acid (TFA) [1]. This medium maximizes solubilization of peptides, and proteins are removed in the tissue pellet by centrifugation at $3000 \mathrm{rpm}$ for $10 \mathrm{~min}$ at $4^{\circ} \mathrm{C}$. The supernatants were injected directly onto the HPLC column. The peptides extracted from the NILs were separated by reversed-phase HPLC using an acetonitrile (MeCN, HPLC grade, J.T. Baker Chemicals B.V., Deventer, The Netherlands) solvent system containing $0.1 \%$ TFA (HPLC grade, Merck, Schuchardt, F.R.G.) as described [8]. The peptides were eluted from the $\mathrm{C}_{18} \mu$ Bondapak column $(300 \times 3 \mathrm{~mm}$ i.d.; Waters Associates, Milford, MA, U.S.A.) using a linear gradient from 8 to $52 \%$ $\mathrm{MeCN}$ over $1 \mathrm{~h}$ at a flow rate of $1 \mathrm{ml} / \mathrm{min}$. One-minute fractions were collected and counted by liquid scintillation. The amounts of POMC peptides in the tissue were estimated by ultraviolet absorbance at $210 \mathrm{~nm}$.

The HPLC profile from NIL extracts of representative lesioned and control animals are compared in Fig. 1A and B. The extracts of NILs from lesioned animals

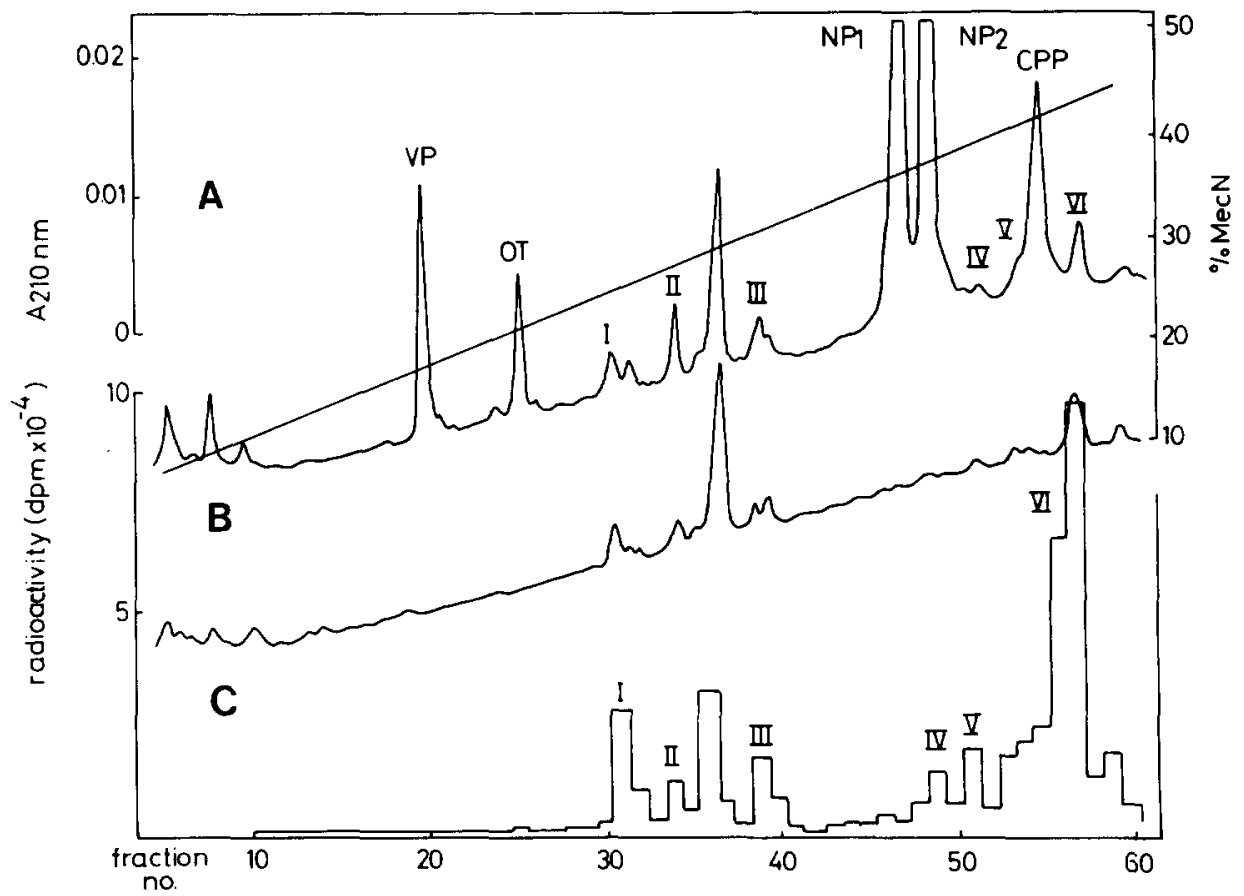

Fig. 1. Separation by reversed-phase HPLC of the peptides extracted from single NILs from a representative control (A) and lesioned (B) rat following incubation with ${ }^{3} \mathrm{H}$-amino acids. The radioactivity in each fraction of $\mathrm{B}$ is shown in $\mathrm{C}$, expressed in dpm of ${ }^{3} \mathrm{H}\left(\times 10^{-4}\right)$. The chromatographic conditions are as described in Methods. The identities of the neural lobe products are shown above the corresponding peaks: VP, vasopressin; OT, oxytocin; $\mathrm{NP}_{1}$, oxytocin-associated neurophysin; $\mathrm{NP}_{2}$, vasopressin-associated neurophysin; CPP, carboxyl-terminal propressophysin. Several peaks which contained relatively pure peptides derived from POMC were selected. Their identities, determined by their relative elution positions [7], are the following: I, [Lys'] $\gamma_{3} \mathrm{MSH}$ (i.e. POMC $\mathrm{PO}_{50-74}$ ); II, di-acetylated $\alpha-\mathrm{MSH}$; III, phosphorylated and nonphosphorylated $\mathrm{ACTH}_{18-39}$ (i.e. CLIP); IV, acetylated $\beta$-endorphin - $_{1-31} ; \mathrm{V}$, acetylated $\beta$-endorphin - $_{1-27}$; VI, POMC $_{1-74}$ (i.e. $16 \mathrm{~K}$ fragment). The same nomenclature applies to Tables I and II. 
(Fig. 1B) show an almost complete absence of neural lobe peptides. The decrease in vasopressin (VP), oxytocin (OT), the two associated neurophysins ( $\mathrm{NP}_{1}$ and $\mathrm{NP}_{2}$ ) and the C-terminal propressophysin (CPP) was used as an indication of the completeness of the lesion. As shown in Table I, an almost 10-fold decrease was observed in the content of VP, OT, NP, $\mathrm{NP}_{2}$ and CPP one week after the lesion $(P<0.001,2$-way ANOVA). These results agreed well with the increase in water consumption starting at 3 days after surgery. The lesioned animals drank $28.3 \pm 3.9 \mathrm{ml} / \mathrm{h} \cdot \mathrm{kg}( \pm$ S.E.M., $n=6)$ on days 4 and 5 while in the same period the controls drank $7.9 \pm 1.0 \mathrm{ml} / \mathrm{h} \cdot \mathrm{kg}$ $(n=6)(P<0.01$, Student's $t$-test) and the 3-fold difference in water consumption was maintained until the day of sacrifice.

The products I-VI which were selected as representative POMC peptides were quantitated by UV absorbance in the HPLC profiles. The identities of the chosen peptides (see legend to Fig. 1) were assigned by comparing their elution positions with those obtained in a previous study in which the same HPLC conditions were employed [7]. As shown in Table I, a small but significant decrease in the total content of POMC peptides was detected in the extracts $(P<0.001,2$-way ANOVA). When the effect of the lesion on the relative ratios of the peptides was tested, 2-way interactions revealed no significant changes in processing by ANOVA: $F_{5,77}=1.28$. Careful inspection of the shape of the peaks revealed a change in the double peak III which contains phosphorylated and non-phosphorylated CLIP [6].

The amount of radioactivity incorporated into each peptide in the control preparations agreed approximately with the predicted molar ratios. The incorporation of ${ }^{3} \mathrm{H}$

\section{TABLE I}

\section{TISSUE CONTENTS OF NIL PEPTIDES IN LESIONED AND CONTROL RATS}

The results are expressed as units of optical density $\left(\times 10^{-2}\right)$ per NIL $( \pm$ S.E.M.) at an absorbance of $210 \mathrm{~nm}$. A 2-way ANOVA was performed for both sets of data. The decrease in peptide content of both lobes with the lesion was highly significant: $F_{1,49}=205.3(P<0.001)$ for the posterior lobe and $F_{1.77}=16.2$ $(P<0.001)$ for the IL.

\begin{tabular}{lcl}
\hline Source peptide & Sham $(n=7)$ & Lesion $(n=6)$ \\
\hline Post. lobe & & \\
VP & $9.2 \pm 1.0$ & $1.2 \pm 0.4$ \\
OT & $5.5 \pm 0.7$ & $0.6 \pm 0.2$ \\
$N_{1}$ & $30.7 \pm 2.4$ & $3.3 \pm 1.3$ \\
$N_{2}$ & $38.2 \pm 4.5$ & $4.4 \pm 1.6$ \\
CPP & $9.1 \pm 0.5$ & $2.1 \pm 0.4$ \\
Int. Lobe & & \\
I & $2.8 \pm 0.09$ & $2.3 \pm 0.3$ \\
II & $1.1 \pm 0.04$ & $0.9 \pm 0.1$ \\
III & $2.4 \pm 0.1$ & $1.8 \pm 0.2$ \\
IV & $0.9 \pm 0.1$ & $0.9 \pm 0.2$ \\
V & $2.3 \pm 0.1$ & $1.8 \pm 0.4$ \\
VI & $3.9 \pm 0.13$ & $2.9 \pm 0.5$ \\
\hline
\end{tabular}


TABLE II

INCORPORATION OF ${ }^{3} \mathrm{H}$ INTO SELECTED IL POMC PEPTIDES IN CONTROL AND LESIONED RATS

The results are expressed as $\mathrm{dpm}\left(\times 10^{-3} \pm\right.$ S.E.M.) incorporated per peptide, following incubation with tritiated amino acids for $24 \mathrm{~h}$. The peptides II and $\mathrm{V}$ were not used because they did not represent a distinct peak in the radioactivity profiles. An ANOVA was used to reveal a significant increase in incorporation in the lesioned rats $\left(F_{1,27}=6.67, P<0.018\right)$.

\begin{tabular}{lrrl}
\hline Peptide & \multicolumn{1}{c}{ Control } & Lesioned & Fold increase \\
\hline I & $24.0 \pm 5.6$ & $36.0 \pm 4.9$ & 2.3 \\
III & $17.4 \pm 4.9$ & $70.6 \pm 5.2$ & 4.0 \\
IV & $64.1 \pm 2.1$ & $160.4 \pm 37.4$ & 2.5 \\
VI & $239.5 \pm 36.0$ & $591.7 \pm 161.7$ & 2.5 \\
\hline
\end{tabular}

into 4 POMC peptides (I, III, IV and VI) was increased up to 4-fold $(P<0.018,2$-way ANOVA) in the lesioned animals (Table II). A sample profile of ${ }^{3} \mathrm{H}$ incorporation into the NIL of a lesioned animal is shown in Fig. 1C. No change in the relative ratios of the products was detected from the incorporation profiles or by examining 2-way interactions by ANOVA: $F_{3,27}=2.37$.

In the present study, the incorporation of tritiated amino acids into NIL explants showed that the lesion could induce up to 4-fold increases in the rate of POMC synthesis in the denervated NIL accompanied by a small decrease in the content of POMC peptides in the tissue. HPLC analysis of the labelled products and total content in the tissue extracts showed no difference in the relative ratio of peptides, indicating no major change in POMC processing. The only possible exception is the change in shape in peak III. This may represent a decrease in the extent of phosphorylation of CLIP [6]. The level of phosphorylation is also different in the IL and AL and may be a physiologically unimportant post-translational modification [2]. The level of all other peptides suggest that the rate of POMC cleavage and post-translational modification increases proportionately with the increased rate of biosynthesis.

The exact mechanism for the increase in POMC biosynthesis is not clear. The hypothalamic lesion which was performed resulted in denervation of the NIL and had dramatic consequences for the rat. The cutting of magnocellular vasopressinergic neurons increased water consumption by depleting the neural lobe of VP. The observed effect is the net result of the diminution of many different factors, namely DA, GABA and serotonin $[4,20]$ as well as other inputs of unknown character. A decrease in the inhibitory influence of the first two neurotransmitters is the most likely explanation for the increase in POMC synthesis. Previous studies using the DA antagonist haloperidol showed an increase in release as well as POMC gene expression $[8,15], N$-acetyltransferase activity [17] and endoproteolytic cleavage of $\beta$-endorphin [19]. These changes were attributed to an antagonism of the tonic DA inhibition.

It may be assumed that the release of POMC peptides was increased in lesioned NILs, as was also reported in the hypothalamo-pituitary disconnected sheep [10]. A 
decrease in POMC peptide immunoreactivity in the IL was also observed after pituitary stalk transection [13] which also eliminates neural inputs to the IL. However, the small decrease in POMC peptides observed in the tissue illustrates that the tissue content cannot be used alone as an index of changes in the rate of biosynthesis. The tissue contents merely reflect the net balance between peptide synthesis and release. At present, it can be concluded that the increase in POMC synthesis following IL denervation may be a direct consequence of the loss of inhibitory inputs or the indirect result of the induction of a new phenotype in these cells.

M.A.S. is supported by the MRC of Canada, H.H.M. v. T. is supported by the Netherlands Organization for Pure Research (ZWO) project 13-49-44.

I Bennet1, H.P.J., Browne, C.A. and Solomon, S., Purification of the two major forms of rat pituitary corticotropin using only reversed-phase HPLC, Biochemistry, 20 (1981) 4533-4538.

2 Bennett, H.P.J., Brubaker, P.L., Seger, M. and Solomon, S., Human phosphoserine 31 corticotropin $_{1-39}$ : isolation and characterization, J. Biol. Chem., 258 (1983) 8108-8112.

3 Bennett, H.P.J., Isolation and characterization of the 1 to 49 amino-terminal sequence of POMC from bovine posterior pituitaries, Biochem. Biophys. Res. Commun., 125 (1984) 229-236.

4 Björklund, A., Moore, R.Y., Nobin, A. and Stenevi, U., The organization of tubero-infundibular catecholamine neuron systems in the rat brain, Brain res., 51 (1973) 171-191.

5 Browne, C.A., Bennett, H.P.J. and Solomon, S., The isolation and characterization of $\gamma_{3}$-melanotropin from the neurointermediate lobe of the rat pituitary. Biochem. Biophys. Res. Commun., 100 (1981) $336-343$.

6 Browne, C.A., Bennett, H.P.J. and Solomon, S., Isolation and characterization of corticotropin and melanotropin-related peptides from the neurointermediate lobe of the rat pituitary by reversed-phase liquid chromatography, Biochemistry, 20 (1981) 4539-4546.

7 Browne, C.A., Bennett H.P.J. and Solomon, S., The isolation of peptides by HPLC using predicted elution positions, Anal. Biochem., 124 (1981) 201-208.

8 Chen, C.L.C., Dionne, F. and Roberts, J.L., Regulation of the POMC mRNA levels in rat pituitary by dopaminergic compounds, Proc. Natl. Acad. Sci. USA, 80 (1983) $2211-2215$.

9 Chrétien, M. and Seidah, N.G., Chemistry and biosynthesis of proopiomelanocortin, Mol. Cell. Biochem., 34 (1981) 101-127

10 Clarke, I.J., Clements, J., Cummins, J., Dench, F., Smith, I.A., Robinson, P. and Funder, J., Elevated plasma levels of pro-opiomelanocortin-derived peptides in sheep following hypothalamo-pituitary disconnection, Neuroendocrinology, 44 (1984) 508-514.

11 Eipper, B.A. and Mains, R.E., Structure and biosynthesis of proadrenocorticotropin/endorphin and related peptides, Endocrinol. Rev., 1 (1980) 1-27.

12 Eipper, B.A., Mains, R.E. and Glembotski, C., Identification in pituitary tissue of a peptide $\alpha$-amindation activity that acts on glycine extended peptides and requires molecular oxygen, copper and ascorbic acid, Proc. Natl. Acad. Sci. USA, 80 (1983) 5144-5148.

13 Friedman, E., Krieger, D.T., Leranth, C., Mezey, E., Brownstein, M. and Palkovits, M., Serotonergic innervation of the rat pituitary intermediate lobe: decrease after stalk section, Endocrinology, 112 (1983) $1945-1947$.

14 Glembotski, C., Characterization of the peptide acetyltransferase activity in bovine and rat intermediate pituitaries responsible for the acetylation of $\beta$-endorphin and $\alpha$-melanotropin, J. Biol. Chem., 257 (1983) $1050 \mathrm{I}-10509$.

15 Hölt, V., Haarmann, I., Seizinger, B.R. and Herz, A., Chronic haloperidol treatment increases the level of in vitro translatable mRNA coding for the $\beta$-endorphin/adrenocorticotropin precursor POMC in the pars intermedia of the rat pituitary, Endocrinology, 110 (1982) 1885-1891. 
16 Liotta, A.S., Yamagushi, H. and Krieger, D.T., Biosynthesis and release of $\beta$-endorphin, $\mathrm{N}$-acetyl $\beta$ endorphin, $\beta$-endorphin ${ }_{1-27}$ and $\mathrm{N}$-acetyl $\beta$-endorphin ${ }_{1-27}-1$ like peptides by rat pituitary neurointermediate lobes: $\beta$-endorphin is not further processed by the anterior lobe, J. Neurosci., 1 (1981) 585-595.

17 Millington, W.R., O’Donohue, T.L., Chappell, M.C., Roberts, J.L. and Mueller, G.P., Coordinate regulation of peptide acetyltransferase activity and POMC gene expression in the intermediate lobe of the rat pituitary, Endocrinology, 118 (1986) 2024-2033.

18 Randle, J.C.R., Moor,B.C. and Kraicer, J., Differential control of the release of POMC-derived peptides from the pars intermedia of the rat pituitary: response to serotonin, Neuroendocrinology, 37 (1983) 131-140.

19 Smith, A.I., Wallace, C.A., Autelitano, D.J., Cheng, M.C., Clarke, I.J. and Funder, J.W., $\alpha$-N-Acetylated $\beta$-endorphin is differentially processed in the normal and hypothalamo-pituitary-disconnected (HPD) ewe, Neurosci. Lett., 65 (1986) 229-233.

20 Tappaz, M.L., Kakucska, I., Paut, L. and Makara, G.B., Decreased GABAergic innervation of the pituitary intermediate lobe after rostral hypothalamic cuts, Brain Res., Bull., 17 (1986) 71 I-716.

21 Tomiko, S.A., Taraskevich, P.S. and Douglas, W.W., GABA acts directly on cells of the pituitary pars intermedia to alter hormone output, Nature (London), 301 (1983) 706-707. 